\title{
A Utilização do Software Educacional "Aprenda Scratch" no Letramento em Programação por Alunos de Curso Técnico em Informática a Distância
}

\author{
Heyder Vágner Ramos', Marcia Oliveira², Marize Lyra Silva Passos², \\ Rodolfo dos Reis Fontes Novais ${ }^{3}$ \\ ${ }^{1}$ Instituto Federal do Espírito Santo campus Vitória (IFES) \\ ${ }^{2}$ Centro de Referência em Formação e em Educação a Distância (CEFOR) \\ ${ }^{3}$ Instituto Federal do Espírito Santo campus Colatina (IFES)
}

heyderamos@gmail.com, clickmarcia@gmail.com, marize@ifes.edu.br, rodolfoncolatinalgmail. com

\begin{abstract}
Resumo. Por apresentar sintaxe complexa e extensa, a programação sempre foi um grande desafio dos cursos que envolvem informática. O software educacional Aprenda Scratch surgiu em 2015 para tentar facilitar o processo de aprendizagem da programação. Trata-se de um software educacional web que auxilia alunos a utilizarem o Scratch de forma independente. $O$ software foi utilizado por 298 alunos do Curso Técnico em Informática à Distância do Ifes. A experiência se mostrou bastante exitosa: $90 \%$ afirmou que o Aprenda Scratch facilitou a compreensão dos conceitos da linguagem de programação, enquanto 89\% considerou que a experiência serviu para construir uma base para o aprendizado de linguagens mais complexas.
\end{abstract}

\begin{abstract}
With complex and extensive syntax, programming has always been a great challenge in courses involving computer science. The Aprenda Scratch was developed in 2015 to try to make the learning process of programming easer. It is a web education software that helps students use Scratch independently. The software was used by 298 students of the Technical Course in Informatics at a Distance from Ifes. The experience proved to be quite successful: $90 \%$ stated that the Learning Scratch has facilitated the understanding of programming language concepts, while $89 \%$ considered that the experience served to build a basis for learning more complex languages.
\end{abstract}

\section{Desafios e Soluções na aprendizagem da Linguagem de Programação}

A Programação sempre foi um grande desafio dos cursos que envolvem informática, sejam eles de nível técnico ou superior. Por apresentarem sintaxes complexas e extensas, mais adequadas para ambientes de desenvolvimento industrial do que aos meios acadêmicos, as linguagens de programação são de difícil compreensão para a maioria dos alunos, sobretudo àqueles que estão tendo contato com elas pela primeira vez. No Instituto Federal do Espírito Santo - Campus Colatina, o problema também pôde ser observado nas disciplinas do curso técnico a distância. Em 20 de setembro de 2012 a direção geral do campus publicou a Portaria $\mathrm{N}^{\circ} .332$ com o objetivo de estudar as causas da evasão escolar nos últimos 03 anos. $O$ parecer da comissão constatou o seguinte:

Foi aplicado um questionário aos alunos evadidos para melhor compreender as causas da evasão nos diversos cursos do campus. Para este artigo são de interesse os dados obtidos pela comissão para o curso técnico de Informática a distância. 
Participaram da pesquisa alunos evadidos nos períodos de 2011/1, 2011/2, 2012/1 e 2012/2. Uma das principais conclusões dessa comissão é que: as disciplinas de programação de computadores são uma das principais causas da evasão, pela sua dificuldade "natural", pela falta de base do ensino médio e até por falta de uma melhor estratégia para tratar conteúdos e desenvolver avaliações por parte do corpo docente. (TEIXEIRA, 2014, p. 4)

Reafirmando os dados percebidos pelo questionário, uma pesquisa finalizada em 2013 no mesmo campus mostrou que os cursos: Técnico em Informática, Tecnologia em Redes de Computadores e Bacharelado em Sistemas de Informação obtiveram altas taxas de evasão, sendo elas de $28,2 \%, 61 \%$ e $24 \%$, respectivamente.

$\mathrm{O}$ problema tem sido explicado devido à exigência intelectual que a disciplina requer de seus alunos. Segundo o professor Renan Osório Rios (2015, p. 3), um dos professores do Instituto em questão, "as disciplinas de programação inicial nos cursos de informática possuem conhecimentos que são considerados complexos para serem aprendidos".

O Letramento em programação compreende o desenvolvimento de habilidades iniciais necessárias ao indivíduo que deseje programar em determinada linguagem, ela surge como uma possibilidade de ajudar tais alunos deficitários, já que o desenvolvimento da habilidade de programar poderia auxiliar não somente na própria disciplina de programação, mas além disso, podendo ser úteis a outras áreas como lógica, gramática ou matemática.

O Scratch é uma linguagem que visa tornar o processo de letramento em programação algo mais fácil, intuitiva e se utilizando de elementos gráficos para apoiar o ensino de noções básicas de programação, o projeto é do grupo Lifelong Kindergarten no Media Lab do MIT (Instituto de Tecnologia de Massachusets), idealizado por Mitchel Resnick e disponível em mais de 150 países.

Diferentemente das linguagens de programação compostas puramente por elementos textuais, o Scratch trabalha com blocos lógicos e itens de som e imagem que são programados e acionados por comandos tipo "clique e arraste", o que possibilita seu aprendizado até mesmo por crianças.

Tendo em vista a necessidade de ações para melhorar a compreensão dos alunos quanto à linguagem de programação e, sabendo-se da possibilidade do uso da ferramenta Scratch, professores do Ifes campus Colatina levaram aos seus alunos do curso de Redes de Computadores a demanda para a criação de um software educacional que permitisse aos alunos o aprendizado da linguagem de forma mais autônoma.

Destes esforços surgiu em 2014 o software educacional Aprenda Scratch. A seguir veremos como o software foi desenvolvido, como fui utilizado no Letramento em Programação e como esta utilização facilitou a compreensão da linguagem de programação pelos alunos do curso técnico de informática a distância do Ifes.

\section{O Software Educacional Aprenda Scratch}

O Scratch é uma linguagem simplificada. Ela utiliza blocos lógicos coloridos quepodem ser arrastados e encaixados, assim como peças de lego, formando as sequências de programação na tela. A figura 1 mostra uma comparação entre as duas linguagens Scratch com utilização gráfica de blocos e Hypertext Preprocessor (PHP), uma linguagem tradicional em texto. 
Apesar dessa simplificação, o Scratch não garante aos alunos compreensão facilitada da lógica de programação, sendo necessário o devido direcionamento na utilização da linguagem. Devido a tal necessidade, o Aprenda Scratch foi desenvolvido no intuito de ser uma plataforma online que direcionasse e acompanhasse o aluno da Educação a Distância (EAD) no aprendizado da linguagem Scratch.
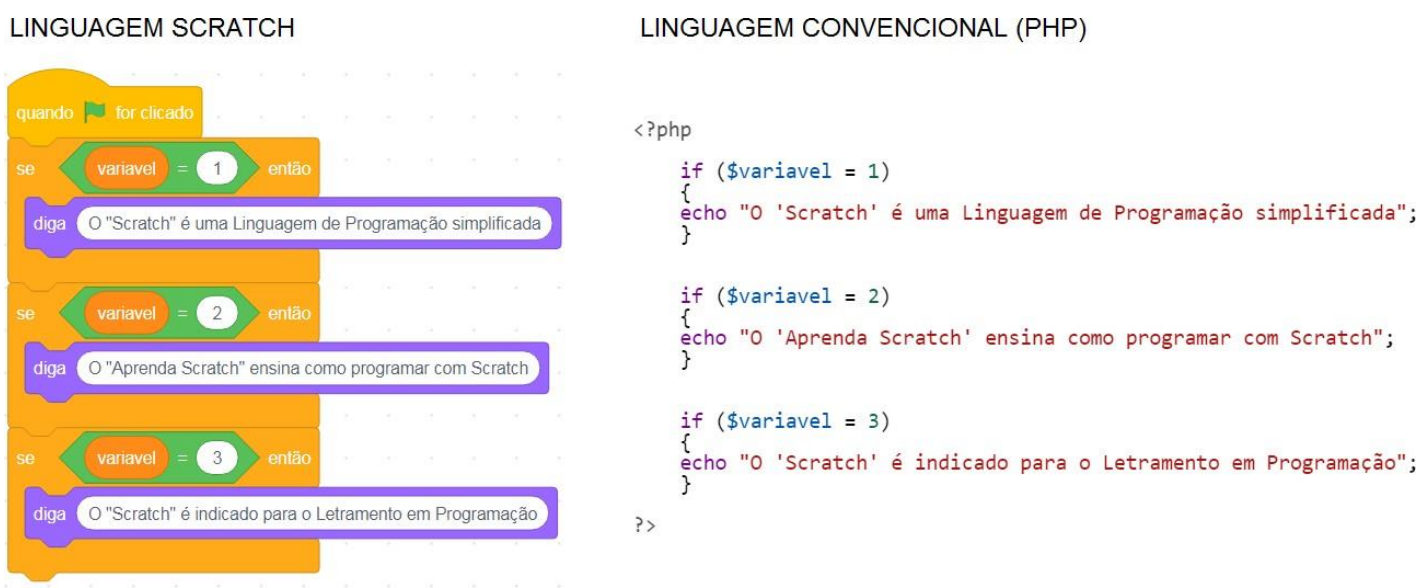

FIGURA 1. Comparação entre uma linguagem convencional e o Scratch

No projeto do Aprenda Scratch, os desenvolvedores consideraram o fato de que o aluno de Educação a Distância estaria fazendo o curso sem o auxílio imediato do professor, provavelmente em sua casa, sozinho, em horários alternativos e flexíveis. Foi tomado o devido cuidado para que o curso fosse algo possível de ser realizado nesses moldes, de forma autônoma, bem como que os conteúdos sejam apresentados de forma gradativa. Demonstraremos a seguir algumas das funcionalidade do software.

O software educacional Aprenda Scratch se baseia fundamentalmente em três etapas: 01) acesso a videoaula; 02) Atividade prática a respeito da videoaula; 03) Atividade teórica - resolução de exercícios referentes à videoaula, seguido de exibição de resultados.Além da utilização de recursos de áudio e vídeo, o software se preocupa em não permitir que o aluno pule etapas no processo de aprendizagem. Não é possível acessar a segunda videoaula sem antes acessar e resolver as atividades relativas à primeira, e assim sucessivamente. Deste modo, o software segue desbloqueando as próximas fases na medida em que fases anteriores são concluídas.

A página de exibição da videoaula (Figura 2) exibe um iframe de incorporação do vídeo previamente disponibilizado no Youtube. Além disso, exibe a opção de visualizar a mesma videoaula feita em uma versão inferior do Scratch, a 1.4. Abaixo da janela de vídeo, temos a opção de baixar a videoaula em qualidade $720 \mathrm{p}$, também em ambas versões. A página de exibição de exercícios (Figura 1) também exibe um iframe com os exercícios para cada etapa. Para cada uma das videoaulas do curso é exigido exercício composto por 10 perguntas.

Cada pergunta do bloco de exercícios é baseada no conteúdo anteriormente praticado e composta por uma imagem e quatro opções de resposta, contendo apenas uma opção correta. Ao selecionar a resposta que julga ser correta e acionar o botão "Enviar resposta", o sistema faz a conferência da questão e exibe o resultado instantaneamente, confirmando o acerto ou demonstrando o erro do usuário. O sistema exibe as perguntas aleatoriamente, de modo a evitar que usuários compartilhem entre si as respostas, e registra a pergunta já realizada de modo que o usuário não responda a mesma pergunta duas vezes. 
Também é possível interromper a sessão de exercícios e voltar a ela mais tarde, em uma nova sessão. Entretanto, não é possível refazer uma seção de exercícios.

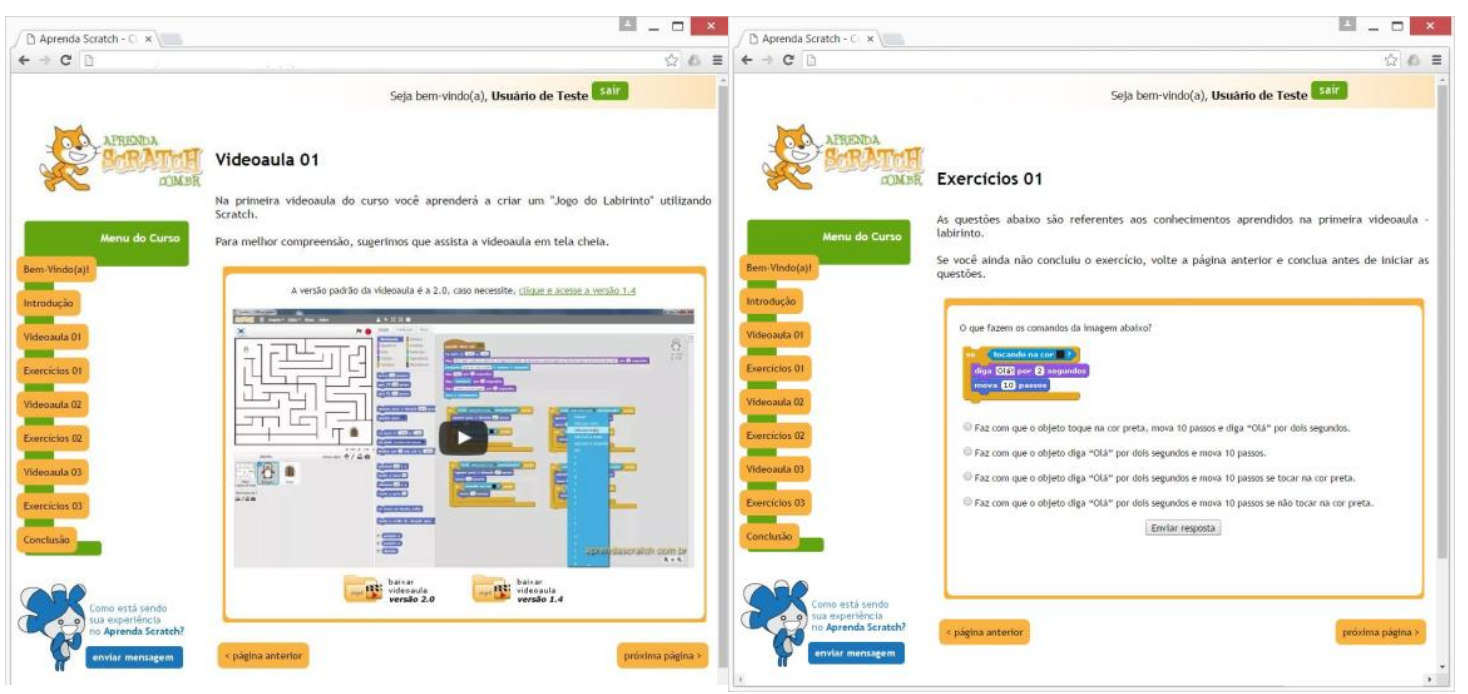

Figura 2: Página de Exibição da videoaula e exercícios

Como o curso de programação proposto é gradativo e sem mediação direta de tutor ou algo semelhante, a finalidade do controle de meio é impedir que o usuário complete a sequência de exercícios com nota muito baixa e prossiga com o curso sem o devido conhecimento da fase que concluiu.

Após finalizar todas as seções de exercício, a página de conclusão aparecerá completa. No exemplo (Figura 03) temos um Usuário de Teste com a totalidade de pontos distribuídos no curso. Nesta fase, o botão "Emitir Certificado" fica ativo, possibilitando que o usuário faça a emissão do comprovante de conclusão em um arquivo *.pdf.

O certificado de conclusão exibe a carga horária do curso (20 horas) e a porcentagem do desempenho geral do concluinte (Figura 03).

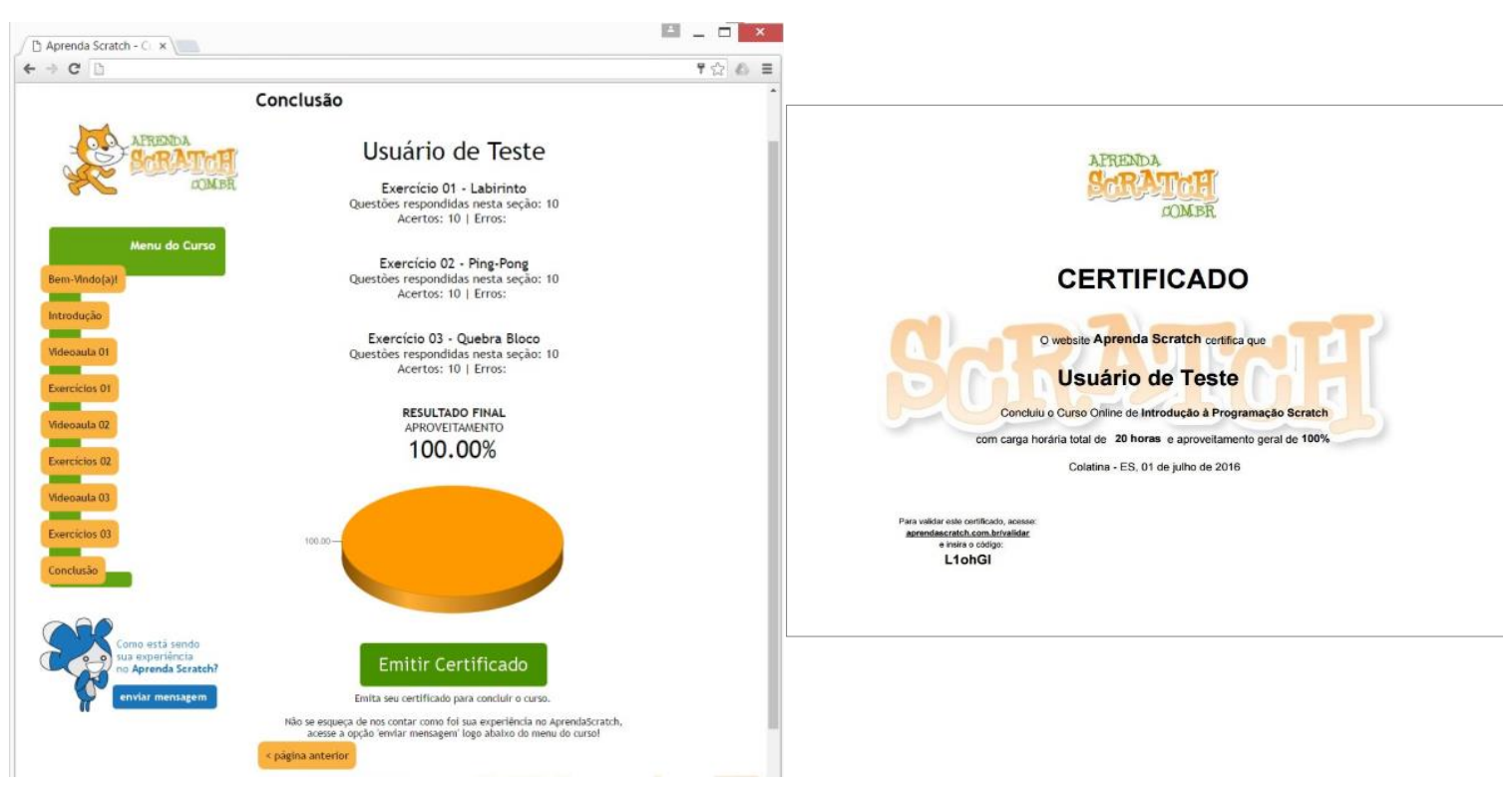

Figura 03: Exibição de relatório geral de usuário concluinte. Opção "Emitir Certificado" ativa. Exemplo de certificado 
Além disso, o certificado traz também um código de validação. Cada certificado possui um código único gerado pelo sistema. A validação pode ser efetuada por qualquer pessoa, bastando para isso acessar o link e digitar o código alfanumérico descrito no certificado.

Esta funcionalidade foi uma solicitação de um dos professores do Ifes campus Colatina e tem como objetivo evitar a fraude dos certificados, já que exibe os dados de desempenho exatamente como foram obtidos pelo usuário na execução do curso. Deste modo, o professor que recebe os certificados dos alunos pode acessar a página do site e conferir se os dados do certificado são verídicos.

Todas as funcionalidades do software educacional - linguagens de programação e programas utilizados, estrutura de banco de dados, casos de uso e detalhes do desenvolvimento estão descritos na documentação do sistema constante do trabalho de conclusão de curso Aprenda Scratch - Software Educacional Web de Apoio à Introdução ao Aprendizado de Programação, já citado anteriormente, e podem ser acessados por interessados através do link http://aprendascratch.mygamesonline.org.

\section{Relato de Experiência e Recomendações de Utilização}

O software foi utilizado por 298 alunos do Curso Técnico em Informática à Distância do Ifes campus Colatina, no primeiro semestre de 2015. Com o auxílio de professores, o software foi disponibilizado aos alunos no início da disciplina de programação. Estes tiveram o prazo de 06 meses para finalizar o curso e submeter o certificado que é gerado no software através do Ambiente Virtual de Aprendizagem (Moodle) do Ifes. Portanto, o Aprenda Scratch, apesar de ser em si um curso de programação inicial, foi utilizado apenas como parte da disciplina de programação do curso técnico. Esta foi a primeira turma do curso que utilizou o software como forma de contato inicial com conceitos da lógica de programação.

Além de finalizar o curso proposto pelo software educacional Aprenda Scratch, que inclui a criação de três jogos distintos, os alunos deveriam, ao final da experiência, desenvolver um jogo totalmente novo e distinto dos que foram aprendidos através do software.

Após o período de utilização do software foi realizada, através de formulário online, pesquisa com os usuários do software a fim de medir o grau de satisfação do usuário e eficiência do software. Dos participantes, $34 \%$ respondeu que teve contato com outra linguagem de programação antes de utilizar o Aprenda Scratch, 30\% depois e 36\% não teve contato antes e nem depois. Ou seja, para $66 \%$, o software foi o primeiro contato com a linguagem de programação.

$\mathrm{O}$ assunto foi complementado pela questão seguinte que arguiu se o Aprenda Scratch lhe serviu como base para aprendizado de linguagens mais complexas, visando demonstrar os efeitos externos da utilização do software, isto é, para além do próprio Scratch em si. Destes, 35\% responderam "bastante", 54\% "um pouco" e 10\% "não facilitou nem atrapalhou". Apenas 1\% escolheu a opção "atrapalhou", um número significativamente baixo.

Analisando a pontuação dos concluintes do curso (Gráfico 01), numa amostra total de 298 usuários, notou-se que 10\% conseguiu nota máxima, perfazendo 100 pontos. A grande maioria dos usuários - 39\% - obteve nota considerada muito alta - entre 90 e 99 pontos. Seguidos de $28 \%$, entre 80 e 89 pontos, $12 \%$ entre 70 e 79 pontos, $6 \%$ entre 60 e 69 pontos, e por fim, apenas $5 \%$ dos concluintes obtiveram rendimento considerado baixo, menos de 60 pontos. 
Tomando por base os resultados dos participantes, apenas 5\% de reprovação, pode-se deduzir que o software Aprenda Scratch conseguiu cumprir bem a proposta de apresentar a Linguagem Scratch, sobretudo considerando que a programação era algo totalmente novo para $66 \%$ dos alunos.

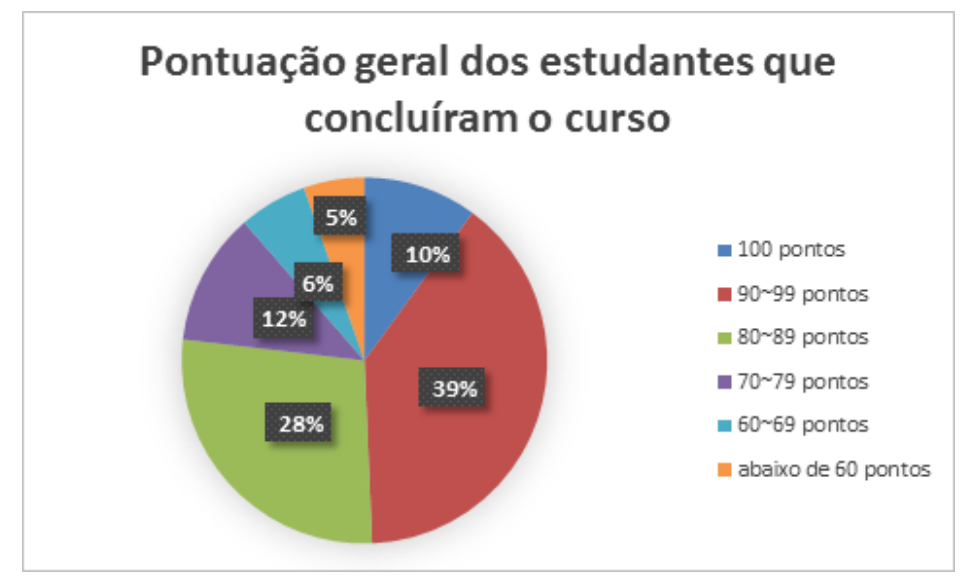

\section{Gráfico 01: Pontuação dos alunos no software Aprenda Scratch}

Foram aplicadas, também, algumas questões abertas com intenção de complementar os dados quantitativos e proporcionar maior liberdade de expressão aos alunos. Inicialmente, temos que o Aprenda Scratch demonstrou-se efetivo para alguns indivíduos que nunca haviam tido contato com a linguagem de programação:

Achei bastante interessante, pois não conhecia nada a respeito e agora eu consigo entender o funcionamento da linguagem de programação. (Aluno Anônimo 1)

O Scratch facilitou bastante a forma inicial de aprendizagem na programação. Aprendemos o que é programação de uma forma bem divertida e legal, fazendo com que aprendêssemos mais, e que gostássemos do que estávamos fazendo. (Aluno Anônimo 2)

Houve comentários que revelam entusiasmo e superação na execução do curso, como se observa a seguir:

Achei interessante, principalmente quando comecei a perceber que os comandos usados eram para nos fazer colocar em prática a matéria que estava sendo estudada. (Aluno Anônimo 03)

$\mathrm{O}$ aprenda Scratch de uma certa forma me ajudou a entender a utilizar os comandos que eu não fazia ideia de como utilizar. É bem complicado de fazer os programas, tem que bastante atenção e ver as video-aulas que dá certo. (Aluno Anônimo 04)

Os alunos também emitiram opiniões a respeito das videoaulas e dos exercícios:

Bom, achei uma plataforma bem simples. Com bastante comandos para criar qualquer tipo de jogo. Achei simples pelo fato de ter bastante videoaula que ensina como usar essa plataforma. (Aluno Anônimo 05)

Os exercícios estão em um dificuldade boa, e com a ajuda dos vídeos é possível fazer bem. (Aluno Anônimo 06)

Quanto a outras observações consideradas importantes, podemos destacar:

Achei muito interessante, pois sou pedagoga do ensino fundamental e o professor de tecnologia começou a ensinar programação no Scratch para os alunos e eles apresentaram bastante facilidade para aprender. (Aluno Anônimo 07) 
Deste modo, fica notória a aceitação do Scratch como ferramenta de introdução a programação inicial, destacando-se por sua simplificação do conteúdo e por sua apresentação da lógica de programação de forma mais facilitada e didática.

\section{Resultados e Reflexões}

O Aprenda Scratch surgiu de uma demanda levantada por professores do Ifes campus Colatina, no ano de 2014. Observava-se grande dificuldade nas disciplinas de programação pelos alunos que ingressavam nos cursos que envolviam informática, por conter conteúdos considerados complexos para serem aprendidos. O problema se agravava mais quando se tratava de um curso a distância, já que não é possível contar com contato direto com o professor para sanar dúvidas. Por muitas vezes, a dificuldade com programação foi fator de desestimulo e até de desistência, gerando evasão nos cursos.

Como vimos, o software se utiliza da linguagem Scratch, que é baseada em elementos gráficos, para tornar o aprendizado dos conceitos de programação mais facilitado. Os resultados tem sido maior facilidade no entendimento da lógica de programação, bem como menor resistência por parte dos alunos no contato com o conteúdo.

Como a experiência foi exitosa no curso de Informática à Distância, professores decidiram utilizar o software também no início do semestre nas turmas de Técnico em informática para Internet integrado ao Ensino Médio desde 2015, a disciplina de programação tem duração de um ano e o software é utilizado no início, durante dois meses. Ele já foi aplicado nas turmas M-10 (36 alunos), M-15 (21 alunos), M-16 (22 alunos), M-17 (26 alunos) e M-18 (24 alunos). Há uma previsão para que o software continue sendo utilizado no ano de 2019, tanto no curso de informática a distância quanto no ensino médio integrado.

Finalizando, o professor da disciplina disse o seguinte:

Acredito que o site Aprenda Scratch foi um sucesso porque foi feito a partir de um TCC do campus Colatina, foi implementado na prática num curso nosso a distância, no qual os alunos não conheciam o Scratch, utilizaram o site e falaram "super bem", facilitou o andamento da disciplina por que os alunos aprenderam primeiro a programar por meio de blocos para só depois aprenderem através da digitação com Python.

Pode-se perceber, através dos comentários feitos pelos alunos durante e depois da experiência com o software e através da opinião do professor da disciplina de programação do curso técnico de informática a distância, que o software educacional Aprenda Scratch cumpre bem o seu papel como ferramenta que visa a simplificação dos conceitos da linguagem de programação. Tanto que foi expandido a outro curso, como o Técnico em Informática para Internet integrado ao Ensino Médio, que é presencial.

Como o software é online e gratuito (http://aprendascratch.mygamesonline.org), torna-se plenamente viável a adaptação desta experiência nas disciplinas de programação de outros cursos e instituições. Inclusive, há possibilidade do uso do software de forma independente, até mesmo sem a mediação do professor, já que o software detém, como vimos no desenvolvimento deste texto, mecanismos para garantir o aprendizado gradual e controlado dos alunos online.

Espera-se que esta experiência sirva de exemplo e inspiração para alunos e professores começarem a utilizar o Aprenda Scratch como ferramenta para o aprendizado dos conceitos de programação e para a criação de uma base para o entendimento de linguagens de programação mais complexas. 


\section{Referências}

LAUDON, K. C., \& LAUDON, J. P. Sistemas de Informação. LTC Editora, $4^{\text {a }}$ Edicação Rio de Janeiro, 1999.

OLIVEIRA, Márcia Gonçalves de et al. O Moodle de Lovelace: Um Curso a Distância de Python Essencial, Ativo e Prático para Formação de Programadoras. Women in Information Technology (WIT_CSBC), [S.1.], v. 12, n. 1/2018, jul 2018. Disponível em: $<$ http://portaldeconteudo.sbc.org.br/index.php/wit/article/view/3375>. Acesso em: 01 dez. 2018.

PAPERT, Seymour. LOGO: Computadores e Educação. Editora Brasiliense, $4^{\text {a }}$ Edição, São Paulo, 1985.

RIOS, Renan Osórios. Projeto de Extensão para o Aprendizado das Competências

Acadêmicas em Programação Inicial. Colatina, 2015.

SOUSA, R. P., MOITA, F. M., \& CARVALHO, A. B. Tecnologias Digitais na Educação. Campina Grande: 2011.

TEIXEIRA, Giovany Frossard. WebAvOO Um Processo Avaliativo Formativo Adaptativo ao Ensino a Distância, Implementação em Disciplina de Programação Orientada a Objetos. Acesso em 28 nov de 2018, disponível em <http://sistemas3.sead.ufscar.br/ojs/index.php/2014/article/viewFile/459/200> 